\title{
Büchner-Miszelle
}

\section{Was den Menschen vom Tier unterscheidet}

\author{
Von Rtchard Thieberger (Nice)
}

Im Büchner-Nachlaß des Goethe- und Schiller-Archivs in Weimar verzeichnet der Katalog eine "Enskriptionsliste" (sic) mit drei Zeilen französ. Text von Georg Büchner. Wenn man das Dokument in Augenschein nimmt, so läßt sich nicht ermitteln, von welcher Universität diese Inskriptionsliste, ein Verwaltungsformular, ausgegeben worden ist, noch welches akademische Jahr sie betrifft. Das nicht ordnungsgemäß ausgefüllte Blatt diente dem von seinen Professoren sichtlich gelangweilten Studiosus Georg Büchner zu zeitvertreibenden Kritzeleien. Neben einigen mehr oder weniger verblaßten Karikaturen finden sich tatsächlich drei Zeilen französischen Textes, darunter der mit einer Wellenlinie unterstrichene Namenszug Georg Büchner. Man errät, wie sich der künftige "Autor" einen bescheidenen Vorschuß auf Dichterlorbeeren gewährt, indem er auf eine schwungvolle Unterschrift trainiert.

Nun aber zum Text, der - nach einiger Mühe - einwandfrei zu entziffern ist. Da steht nun folgendes:

Boire sans soif et faire l'amour en tout temps, il n'y a que ga qui nous distingue des autres bêtes

Georg Büchner

Ob der akademische Lehrer, der den Studenten zu einer solchen Digression anregte, gerade von menschlichen oder von tierischen Funktionen sprach, ist nicht ersichtlich. Daß aber der angehende Mediziner Büchner das Säugetier Mensch von den andern Familien der species mehr oder minder vorteilhaft zu unterscheiden suchte, läßt sich nicht leugnen. Die Verbindungen zu Textstellen aus dem Danton oder dem Woyzeck ergeben sich auf den ersten Blick. Sehr schmeichelhaft kommt das höhere Wesen Mensch hier freilich nicht weg. Denn nur scheinbar wird ihm dem Tier gegenüber eine Überlegenheit zuerkannt: auch ohne Durst zu trinken und "jederzeit" Geschlechtsverkehr zu pflegen. Ist da nicht eher dem Tier die Palme zu reichen, das nur auf ein bestimmtes Bedürfnis hin handelt, also z.B. nur dann trinkt, wenn es Durst hat? Man könnte sich verleiten lassen diese Studentenkritzelei mit Büchners "Kulturpessimismus" in Verbindung zu bringen. Immerhin, der Studiosus trieb hier ernste Spässe ... 